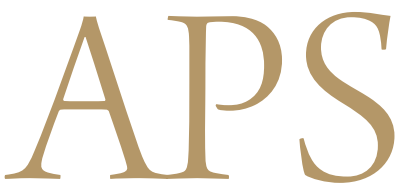

Archives of Plastic Surgery

\title{
Management of Infections with Rapidly Growing Mycobacteria after Unexpected Complications of Skin and Subcutaneous Surgical Procedures
}

\author{
Jong Min Lim, Jong Hwan Kim, Ho Jik Yang \\ Department of Plastic and Reconstructive Surgery, Eulji University Hospital, Eulji University School of Medicine, Daejeon, Korea
}

Background Infection caused by rapidly growing mycobacteria (RGM) is not uncommon, and the prevalence of RGM infection has been increasing. Clinical diagnosis is difficult because there are no characteristic clinical features. There is also no standard antibiotic regimen for treating RGM infection. A small series of patients with RGM infections was studied to examine their treatments and outcomes.

Methods A total of 5 patients who had developed postoperative infections from January 2009 to December 2010 were retrospectively reviewed. Patients were initially screened using a mycobacteria rapid screening test (polymerase chain reaction [PCR]-reverse blot hybridization assay). To confirm mycobacterial infection, specimens were cultured for nontuberculous mycobacteria and analyzed by $16 \mathrm{~S}$ ribosomal RNA and rpoB gene PCR.

Results The patients were treated with intravenous antibiotics during hospitalization, and oral antibiotics were administered after discharge. The mean duration of follow-up was 9 months, and all patients were completely cured of infection with a regimen of a combination of antibiotics plus surgical treatment. Although none of the patients developed recurrence, there were complications at the site of infection, including hypertrophic scarring, pigmentation, and disfigurement.

Conclusions Combination antibiotic therapy plus drainage of surgical abscesses appeared to be effective for the RGM infections seen in our patients. Although neither the exact dosage nor a standardized regimen has been firmly established, we propose that our treatment can provide an option for the management of rapidly growing mycobacterial infection.

Keywords Mycobacterium infections, nontuberculous / Therapy / Antibacterial agents

\author{
Correspondence: Ho Jik Yang \\ Department of Plastic and \\ Reconstructive Surgery, Eulji \\ University Hospital, Eulji University \\ School of Medicine, 95 Dunsanseo-ro, \\ Seo-gu, Daejeon 302-799, Korea \\ Tel: +82-42-611-3029 \\ Fax: +82-42-259-1111 \\ E-mail: drhjyang@yahoo.co.kr
}

Received: 15 Aug 2011 • Revised: 7 Nov 2011 - Accepted: 23 Nov 2011

pISSN: 2234-6163 • elSSN: 2234-6171 • http://dx.doi.org/10.5999/aps.2012.39.1.18・ Arch Plast Surg 2012;39:18-24

No potential conflict of interest relevant to this article was reported.

\section{INTRODUCTION}

There is growing concern about chronic inflammation that is resistant to standard management developing after aesthetic surgeries such as liposuction, fat grafts, and implant insertion. The primary causes of chronic inflammation are thought to be anti- biotic-resistant bacteria and fungi, in addition to rapidly growing mycobacteria (RGM). Nontuberculous mycobacteria (NTM), also known as mycobacteria other than tuberculosis (MOTT), include all the other mycobacteria except the Mycobacterium tuberculosis complex and M. leprae [1]. Atypical mycobacteria were classified in 1950 by Runyan, based on growth rates and 
pigmentation patterns $[1,2]$. NTM have been grouped into 4 broad categories according to the Runyon system. Groups I to III are slow-growing NTM, and group IV are fast growers [3]. Among these organisms, RGM can produce a positive culture within 7 days (e.g., the M. fortuitum group, M. chelonae, and $M$. abscessus) and have emerged as important human pathogens that cause a variety of diseases ranging from localized cutaneous infections to disseminated infections [4]. RGM have been responsible for a number of health care-associated outbreaks and pseudo-outbreaks [1]. Postoperative infections caused by these organisms are not uncommon, and their prevalence is increasing. The clinical presentation includes cellulitis, abscess formation, draining sinuses, and postoperative wound infection. Patients often do not have fever, chills, or other manifestations that are characteristic of a systemic infection, which makes clinical diagnosis difficult [2]. Although RGM infection is common in immunocompromised patients or in patients with antecedent chronic illness, recent studies have shown that RGM infection can also occur in previously healthy patients with a history of surgical procedures such as liposuction or fat grafts $[1,2,5,6]$. Even though infection with RGM is not common, when infec- tion involves areas like the face, it is very problematic to both patients and their physicians because the probability of complete recovery is very low.

\section{METHODS}

The study comprised 5 patients seen from January 2009 to December 2010, who had a history of surgical procedures resulting in abscesses and chronic inflammation. Their medical records were reviewed retrospectively for demographic data, clinical manifestations, clinical features, species of mycobacterium, treatments, and outcome. A case was defined as any convalescent patient seen after a skin and subcutaneous surgical procedure with signs of inflammation of the skin and abscesses or drainage at the original wound site.

Because rapidly growing mycobacterial infections were suspected, mycobacteria rapid screening tests, consisting of a polymerase chain reaction-reverse blot hybridization assay (PCRREBA), were performed. To confirm mycobacterial infection, specimens were cultured for NTM, which requires 6 to 8 weeks, and analyzed by $16 \mathrm{~S}$ ribosomal RNA (rRNA) and rpoB gene

\section{Table 1. Demographic and clinical data of 5 patients with rapidly growing mycobacteria infection}

\begin{tabular}{|c|c|c|c|c|c|c|}
\hline $\begin{array}{l}\text { Sex/Age } \\
(y r)\end{array}$ & $\begin{array}{l}\text { Type of } \\
\text { surgical } \\
\text { procedure }\end{array}$ & $\begin{array}{l}\text { Incuba- } \\
\text { tion } \\
\text { period } \\
\text { (day) }\end{array}$ & $\begin{array}{l}\text { Predominant } \\
\text { clinical } \\
\text { manifestations }\end{array}$ & $\begin{array}{l}\text { Microbiologic } \\
\text { findings }\end{array}$ & Treatment & Follow-up \\
\hline $\begin{array}{l}\text { F/67 } \\
\text { (Case 1) }\end{array}$ & $\begin{array}{l}\text { Autologous fat } \\
\text { graft on both } \\
\text { cheeks }\end{array}$ & 30 & $\begin{array}{l}\text { Erythematous } \\
\text { nodules, induration, } \\
\text { microabscesses along } \\
\text { both cheeks }\end{array}$ & $\begin{array}{l}\text { Mycobacterium } \\
\text { abscessus }\end{array}$ & $\begin{array}{l}\text { In hospital (for } 4 \mathrm{wk} \text { ) } \\
\text { amikacin ( } 500 \mathrm{mg} / \text { day), ciprofloxacin }(200 \mathrm{mg} \mathrm{q} 21 \mathrm{hr} \text { ), } \\
\text { imipenem/cilastatin sodium (1,000 mg q12 hr) } \\
\text { After discharge (for } 6 \mathrm{mo} \text { ) } \\
\text { clarithromycin ( } 500 \mathrm{mg} \mathrm{q} 12 \mathrm{hr} \text { ) }\end{array}$ & $\begin{array}{l}9 \mathrm{mo} \\
\text { cured }\end{array}$ \\
\hline $\begin{array}{l}\mathrm{F} / 50 \\
\text { (Case 2) }^{\text {a) }}\end{array}$ & $\begin{array}{l}\text { Autologous fat } \\
\text { graft on both } \\
\text { cheeks }\end{array}$ & 14 & $\begin{array}{l}\text { Erythematous } \\
\text { nodules, induration, } \\
\text { microabscesses along } \\
\text { both cheeks }\end{array}$ & $\begin{array}{l}\text { Mycobacterium } \\
\text { conceptionense }\end{array}$ & $\begin{array}{l}\text { In hospital (for } 6 \mathrm{wk} \text { ) } \\
\text { amikacin ( } 500 \mathrm{mg} / \text { day), cefoxitin ( } 1 \mathrm{~g} / \text { day), } \\
\text { ciprofloxacin ( } 400 \mathrm{mg} \text { q } 21 \mathrm{hr}) \text {, } \\
\text { oral sulfamethoxazome/trimethoprim ( } 400 / 80 \mathrm{mg} \\
\text { q12 hr), clarithromycin }(500 \mathrm{mg} \text { q12 hr) } \\
\text { After discharge (for } 9 \mathrm{mo}) \\
\text { clarithromycin }(500 \mathrm{mg} \mathrm{q} 12 \mathrm{hr} \text { ), levoflaxacin } \\
\text { (100 mg q12 hr), } \\
\text { sulfamethoxazole/trimethoprim ( } 400 \mathrm{mg} / 80 \mathrm{mg} \mathrm{q} 12 \mathrm{hr} \text { ) }\end{array}$ & $\begin{array}{l}15 \mathrm{mo} \\
\text { cured }\end{array}$ \\
\hline $\begin{array}{l}\mathrm{F} / 34 \\
\text { (Case 3) }\end{array}$ & $\begin{array}{l}\text { Acupuncture on } \\
\text { both arms }\end{array}$ & 7 & $\begin{array}{l}\text { Pustules on both } \\
\text { arms }\end{array}$ & $\begin{array}{l}\text { Mycobacterium } \\
\text { fortuitum }\end{array}$ & $\begin{array}{l}\text { In hospital (for } 5 \mathrm{wk} \text { ) } \\
\text { amikacin ( } 500 \mathrm{mg} / \text { day), ciprofloxacin }(200 \mathrm{mg} \mathrm{q} 12 \mathrm{hr}) \text {, } \\
\text { cefazolin }(1 \mathrm{~g} \mathrm{q} 8 \mathrm{hr}) \\
\text { After discharge (for } 6 \mathrm{mo}) \\
\text { clarithromycin }(500 \mathrm{mg} \mathrm{q} 12 \mathrm{hr}), \text { cefcapene pivoxil } \\
\text { (100 mg q8 hr) }\end{array}$ & $\begin{array}{l}12 \mathrm{mo} \\
\text { cured }\end{array}$ \\
\hline $\mathrm{F} / 50$ & $\begin{array}{l}\text { Filler injection } \\
\text { on glabellar area }\end{array}$ & 7 & $\begin{array}{l}\text { Induration, } \\
\text { microabscesses along } \\
\text { glabellar area \& both } \\
\text { periorbital area }\end{array}$ & $\begin{array}{l}\text { Mycobacterium } \\
\text { fortuitum }\end{array}$ & $\begin{array}{l}\text { In hospital (for } 4 \mathrm{wk} \text { ) } \\
\text { amikacin ( } 500 \mathrm{mg} / \text { day), ciprofloxacin (200 mg q12 hr), } \\
\text { ceftizoxime ( } 1 \mathrm{mg} \mathrm{q} 12 \mathrm{hr} \text { ), } \\
\text { After discharge (for } 4 \mathrm{mo}) \text {, clarithromycin ( } 500 \mathrm{mg} \mathrm{q} 12 \mathrm{hr} \text { ) }\end{array}$ & $\begin{array}{l}6 \mathrm{mo} \\
\text { cured }\end{array}$ \\
\hline$M / 66$ & $\begin{array}{l}\text { Autologous fat } \\
\text { graft on } \\
\text { forehead }\end{array}$ & 21 & $\begin{array}{l}\text { Induration, } \\
\text { microabscesses along } \\
\text { forehead }\end{array}$ & $\begin{array}{l}\text { Mycobacterium } \\
\text { abscessus }\end{array}$ & $\begin{array}{l}\text { In hospital (for } 4 \mathrm{wk} \text { ) } \\
\text { amikacin ( } 500 \mathrm{mg} / \text { day), ciprofloxacin }(200 \mathrm{mg} \mathrm{q} 12 \mathrm{hr} \text { ), } \\
\text { cefazolin }(1 \mathrm{~g} \mathrm{q} 8 \mathrm{hr} \text { ) } \\
\text { After discharge (for } 3 \mathrm{mo} \text { ) } \\
\text { clarithromycin ( } 500 \mathrm{mg} \mathrm{q} 12 \mathrm{hr} \text { ) }\end{array}$ & $\begin{array}{l}3 \mathrm{mo} \\
\text { cured }\end{array}$ \\
\hline
\end{tabular}


PCR. After a positive mycobacteria rapid screening test, each patient was initially treated with surgical debridement and combinations of antibiotics (Table 1). The patients were followed for at least 3 months after discharge.

\section{RESULTS}

The patients consisted of 4 women and 1 man, ranging in age from 34 to 67 years, with a median age of 50 years. Their conditions were initially diagnosed as injection abscesses and treated by repeated incision and drainage, and empirical antibiotics. This treatment was repeated on several occasions ranging over periods of 1 month or more in most cases. The patients presented to us after the lesions became chronic and recurrent, and no etiological diagnosis had been established. None of the patients were malnourished, chronically ill, or immunocompromised. All patients were human immunodeficiency virus-negative.

During hospitalization, each patient received basic antibiotic treatment consisting mainly of intravenous amikacin and ciprofloxacin and adjusted according to results of antibiotic susceptibility testing. Daily surgical treatment, including incision and drainage, curettage, and saline irrigation, was performed as needed for each patient (Table 1). Despite the resolution of infection, complications such as hypertrophic scarring, pigmentation, and disfigurement occurred at the infection sites.

\section{Case 1}

A 67-year-old woman who had undergone autologous fat grafting for cheek augmentation, presented with multiple erythematous nodules, areas of induration, and microabscesses on both cheeks (Fig. 1A). One month after her augmentation procedure, lesions developed on both sides of her face. Incision, drainage, and antibiotic treatment were begun, but the lesions did not resolve. She presented to our hospital 1 month after the lesions had developed. Gram staining and culture were negative. Because RGM infection was suspected, PCR-REBA, staining for acid-fast bacteria (AFB), and cultures for M. tuberculosis and NTM were performed. AFB staining was negative, but $M$. $a b$ scessus was identified by PCR-REBA, and the patient was started on treatment for RGM.

During the 4 weeks of hospitalization, amikacin (500 mg/ day), ciprofloxacin (200 mg, q12 hr), and imipenem/cilastatin sodium (1,000 mg, q12 hr) were given intravenously. Daily incision, drainage, and currettage were also performed and her symptoms improved within 4 weeks. After discharge, the patient was given oral clarithromycin ( $500 \mathrm{mg}, \mathrm{q} 12 \mathrm{hr}$ ) for 6 months, and she was followed an additional 3 months after stopping medication (Fig. 1B).

\section{Case 2}

A 50-year-old female patient who had undergone autologous fat grafting for cheek augmentation, presented with erythematous nodules, indurations, and microabscesses on both cheeks (Fig. $2)$. Initial incision, drainage, and antibiotics were not effective, and she visited our hospital 2 months after the lesions had developed. Routine tests such as Gram staining and culture were all negative. During her hospitalization, she received combination antibiotic therapy because of suspected RGM infection. The initial result of the PCR-REBA screening test was weakly positive, but a mycobacterial infection caused by a species different from the 19 species that can be detected by that test was highly suspected. Therefore a specimen of drainage fluid from a wound was sent for culture and identification to the Asia Pacific Foundation for Infectious Diseases. The NTM isolate that was identified by partial gene sequencing of $16 \mathrm{~S}$ rRNA and $r p o B$ genes was $M$. conceptionense. This is the first reported case of $M$. concep-

\section{Fig. 1. Case 1}

A 67-year-old woman who had undergone autologous fat grafting to both cheeks developed bilateral erythematous nodules and purulent discharge. (A) Before treatment. (B) Three months after leaving the hospital.
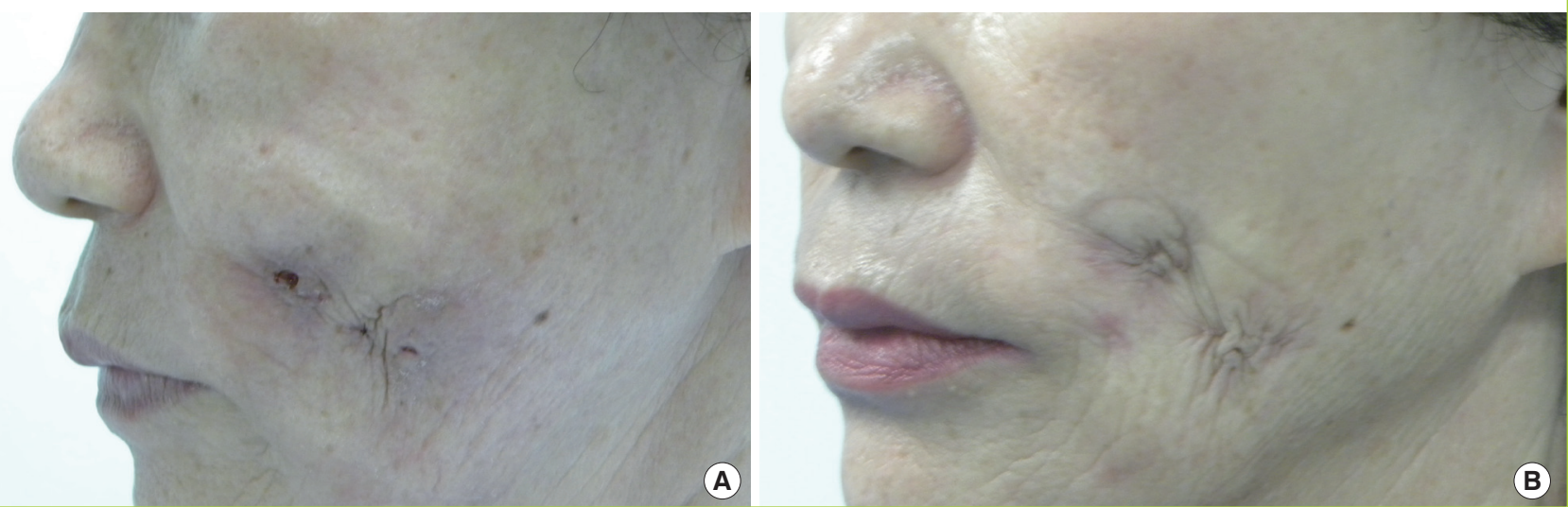
tionense infection followed by aesthetic surgery for fat grafts.

The patient received intravenous amikacin $(500 \mathrm{mg} /$ day $)$, cefoxitin ( $1 \mathrm{~g} /$ day), ciprofloxacin (400 mg, q12 hr), oral sulfamethoxazole-trimethoprim (400/80 mg, q12 hr), and oral clarithromycin (500 mg, q12 hr). Daily incision, drainage, and curettage were also performed during the 6 weeks of her admission. The patient achieved a good response to the combination antibiotic therapy plus wound treatment, with resolution of her lesions. After discharge, she was treated with oral levofloxacin (100 mg, q12 hr), sulfamethoxazole-trimethoprim (400/80 $\mathrm{mg}, \mathrm{q} 12 \mathrm{hr}$ ), and clarithromycin (500 mg, q12 hr). She was followed for 9 months without any relapse (Fig. 3).

\section{Case 3}

A 34-year-old woman who had previously received acupuncture therapy on both arms, presented with pustules on both arms (Fig. 4A). She was treated for 1 month without any response to conventional antibiotic treatment. Because Gram staining, routine culture, and AFB staining were all negative, there was strong suspicion of RGM infection. $M$. fortuitum was identified by the PCR-REBA rapid screening test. Because the skin and soft tissue lesions were highly localized and the surrounding tissues were adequate, a wide excision and primary repair were performed (Fig. 4B). Compared with the other cases, there were no postoperative complications such as pus-like discharge, and the areas of excision resembled typical sutured wounds.

To prevent recurrence, intravenous amikacin $(500 \mathrm{mg} /$ day), ciprofloxacin (200 mg, q12 hr), and cefazolin ( $1 \mathrm{~g}$, q8 hr) were given, during the 4 weeks of the patient's hospitalization. The skin lesions improved within 2 weeks. After discharge, the patient received oral clarithromycin ( $500 \mathrm{mg}, \mathrm{q} 12 \mathrm{hr}$ ), and cefcapene pivoxil ( $100 \mathrm{mg}$, q8 $\mathrm{hr}$ ) for 6 months. The patient was followed for 12 months without complications or recurrence. She was left with small linear scars.

\section{DISCUSSION}

It is very difficult to clinically diagnose RGM infections because

\section{Fig. 2. Case 2}

A 50-year-old woman who had undergone autologous fat grafting to both cheeks developed bilateral erythematous nodules and purulent discharge.
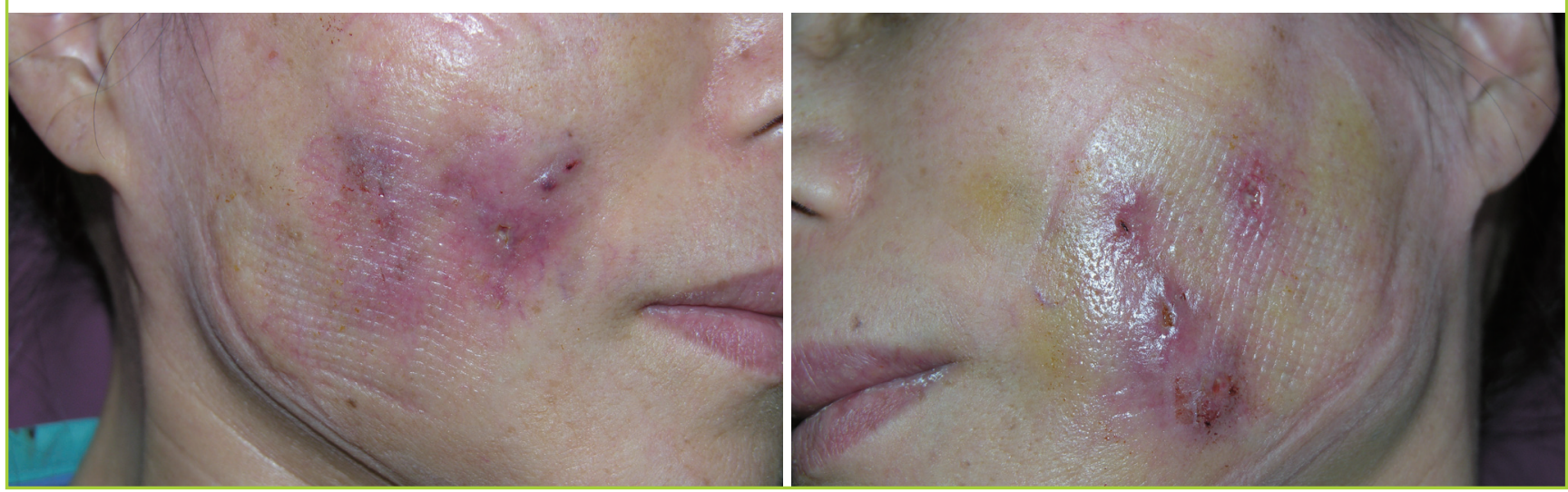

\section{Fig. 3. Case 2}

The patient 6 months after leaving the hospital.

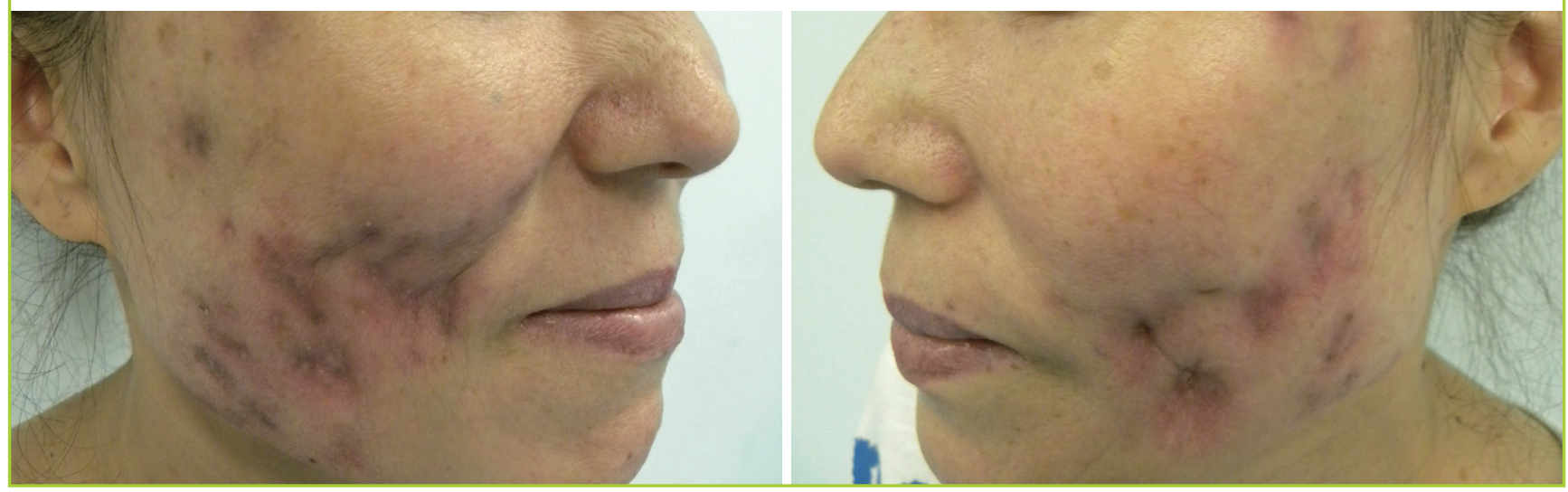




\section{Fig. 4. Case 3}

A 34-year-old woman who developed pustules on both arms after acupuncture. (A) Before treatment. (B) Two years after wide excision.
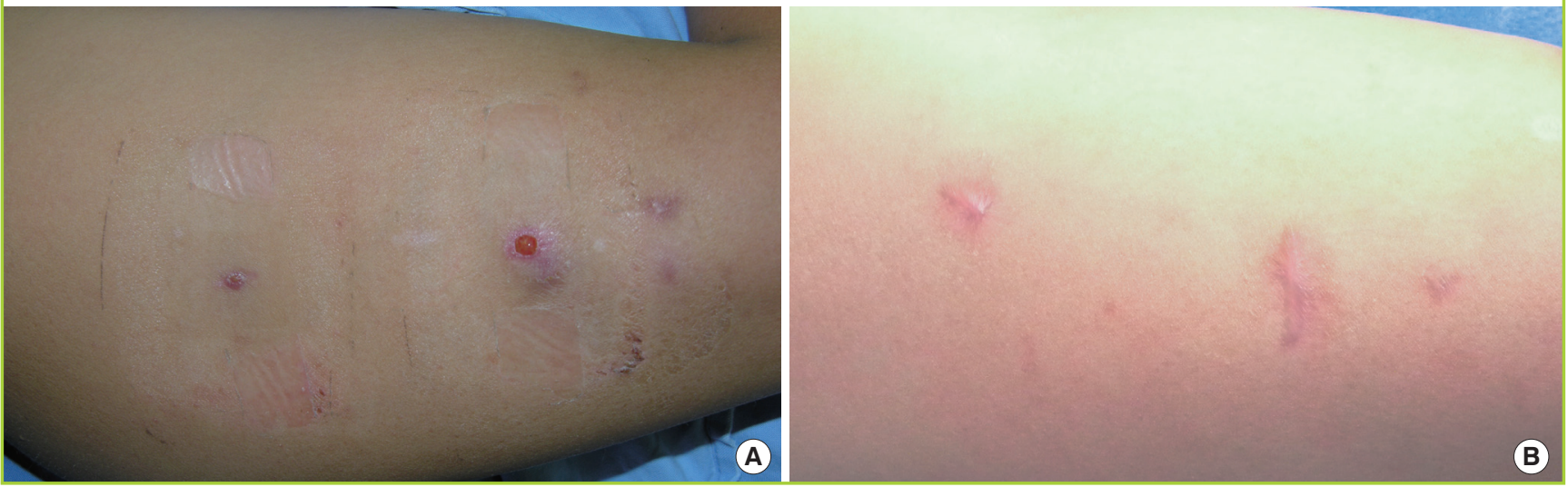

they lack characteristic clinical features. If abscess and chronic inflammation occur after surgical procedures involving skin and subcutaneous tissues, conventional antibiotic treatment is recommended. If there is no response to the treatment, and findings on Gram staining and routine culture are negative, mycobacterial infection should be strongly suspected, and a mycobacteria rapid screening test, AFB staining, and culturing for tuberculosis and NTM organisms should be performed. It usually takes 5 days for results from mycobacteria rapid screening tests to identify microbacterial infections, while it may take up to 6 to 8 weeks for cultures to confirm mycobacterial infection. Therefore, we began antibiotic treatment for RGM infection if it was identified in a rapid screening test, and $16 \mathrm{~S}$ rRNA and $r p o B$ gene PCR analysis were used to identify the species of mycobacteria. Fig. 5 depicts an original flow chart for managing RGM infections that we developed.

PCR-REBA is a useful mycobacteria rapid screening test that can identify the 19 most common species out of the approximately 120 NTM species. These 19 include $M$. avium, $M$. intracellulare, $M$. scrofulaceum, $M$. abscessus, $M$. massiliense, $M$. chelonae, M. fortuitum complex, M. ulcerans, M. marinum, M. kansasii, $M$. genavense, $M$. simiae, $M$. terrae, $M$. nonchromogenicum, M. celatum, M. gordonae, M. szulgai, M. mucogenicum, and M. aubagnense. The test is not only quick but also reliable; the detection level of PCR-REBA for DNA from a cultured isolate or from sputum is $2-20$ bacilli/reaction (or 200 bacilli/mL). The sensitivity of NTM detection is $100 \%$ for DNA specimens from cultured isolates and nearly $100 \%$ for DNA from sputum. The specificity of PCR-REBA is also $100 \%$ for DNA from cultured isolates and sputum DNA sequencing analysis, and $99 \%$ for sputum DNA from cultures on solid media [7]. Although the mycobacteria rapid screening test has high sensitivity and specificity, it can only identify the 19 species previously listed. If a my-

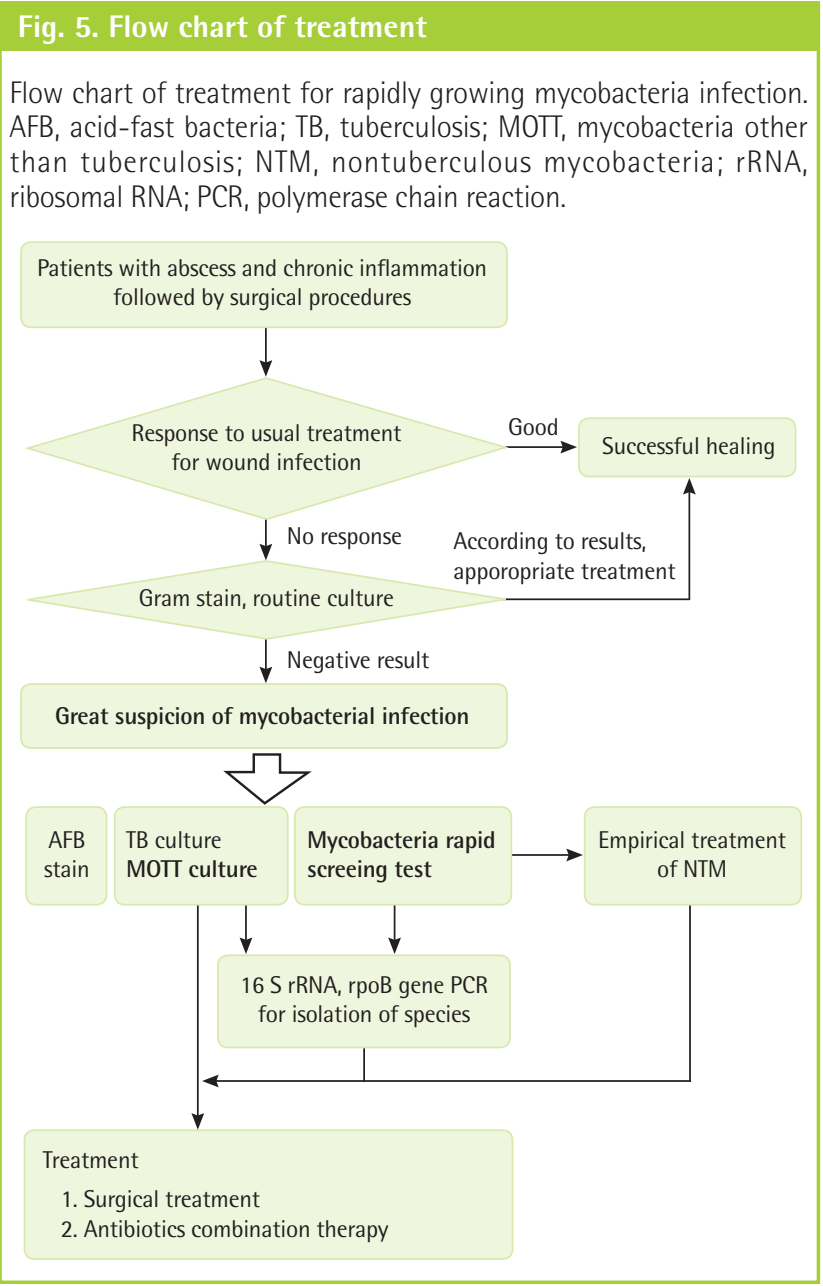

cobacterial infection is strongly suggested even after a negative rapid screening test, a more precise test using $16 \mathrm{~S}$ rRNA PCR can be helpful. $16 \mathrm{~S}$ rRNA gene sequencing has been used as the first line method for identifying unusual mycobacterial isolates [8]. However, there is little variability within the mycobacterial 
$16 \mathrm{~S}$ rRNA gene sequence in RGM, making this target a poor discriminator for closely related species such as M. abscessus and M. chelonae $[9,10]$. For the differentiation and identification of mycobacterial species, the $r p o B$ gene, encoding the $\beta$ subunit of RNA polymerase, and $h s p 65$ genes $(65 \mathrm{kDa}$ heat-shock protein gene) were investigated [10]. According to a recent study by Shin et al., the success rates for NTM identification by targeting the $16 \mathrm{~S}$ rRNA, $r p o B$, and $h s p 65$ genes are $65 \%, 82 \%$, and $87 \%$, respectively. The $h s p 65$ or $r p o B$ gene was more efficient than 16 $S$ rRNA for the identification of NTM by sequencing [9].

Mycobacteria are ubiquitous and have been found in both tap water and soil [1]. The exact pathways of infection have not been determined. However, including cases 1 and 2, three of our five patients had undergone fat graft procedures at the same plastic surgery clinic. Therefore, we believe that contaminated surgical instruments were the source of infection. Reusable surgical instruments in particular, such as the cannulas used in liposuction and fat transfer, are regarded as sources of infection. Mycobacteria cannot be thoroughly killed with the usual disinfectants, and surgical equipment must be autoclaved. If surgical instruments are contaminated with mycobacteria and cannot be autoclaved, special sterilization methods should be used $[1,2]$.

Although autoclaving surgical instruments is the best method for preventing mycobacterial contamination of wounds, reusable instruments such as cannulas, tubings, and fibreoptic cables that can be damaged by autoclaving should be sterilized by immersion in $2 \%$ activated gluteraldehyde solution for 30 minutes to 1 hour, depending on the infectivity of the previous patient's microorganisms. Possible alternative disinfectants include peracetic acid ( $0.2 \%$ to $0.35 \%)$, chlorine dioxide (700-1,100 ppm) and superoxidized water. Ethylene oxide sterilization can also be used for these types of reusable instruments. In addition, mucus or residue from cells on surgical instruments may lead to a significant decrease in disinfecting activity, which means that decontaminating baths must be renewed according to their frequency of use. Rinsing instruments in sterilized water or with $70 \%$ alcohol after disinfection and before use is an excellent method of preventing instrument colonization. Because most RGM infections are iatrogenic, adequate sterilization of surgical instruments, hypodermic needles, suture material, and prosthetic implants is the key to preventing these infections $[1,2]$.

However, it is unclear why only a few patients among the many who underwent procedures in that clinic were infected by mycobacteria, although they had no specific predisposing medical condition, and had normal immune systems. Further research on conditions that would result in vulnerability to mycobacterial infection of the skin and subcutaneous tissues is needed.
In case 3, contaminated acupuncture needles were thought to be the source of infection. Because water is a main source of infecting mycobateria [1], her wound infections could have been caused by contaminated water after the procedure. If the skin and soft tissue lesions are highly localized and there are adequate surrounding tissues, wide excision and primary repair can be a good treatment option. After adequate wide excision, daily debridement is not required. However, infected tissue may remain because it is difficult to determine the appropriate resection margins and depth before and during the operation. Therefore, combination antibiotic therapy should be administered.

It is known that effective treatment of RGM infection includes surgical treatment concurrent with combination antibiotic therapy [6]. An antibiotic combination based on susceptibility of individual isolates must be administered for a sufficiently long period of time to ensure complete wound healing and no recurrence. Conventional antituberculosis drugs have been reported to be ineffective. The choice of antibiotics should depend on in vitro susceptibility patterns, and an antibiotic combination is better than single-drug therapy [11]. Some antimicrobial agents, including quinolones, amikacin, doxycycline, and sulfamethoxazole, have been found to be effective against M. fortuitum. Recent studies have demonstrated that clarithromycin, cefoxitin, and imipenem were also effective against these microorganisms $[2,4,5]$. Based on reported NTM sensitivities, amikacin with ciprofloxacin [2] or amikacin with cefoxitin [6] should be administered to the patient while waiting for microbial sensitivity results, if there is a strong suspicion of atypical mycobacterial infection $[2,6]$. According to results of a study from Brown-Elliott and Wallace [12], the M. fortuitum group is much less drug resistant than M. abscessus and M. chelonae. Thus, treatment of infections caused by the $M$. fortuitum group has been much easier and generally more effective than treatment of M. abscessus and M. chelonae infections.

The therapeutic drugs usually recommended for infections with the M. fortuitum group include amikacin, cefoxitin, imipenem, and fluoroquinolones. Clarithromycin and doxycycline have proven to be effective oral agents $[2,6]$. On the other hand, the recommended treatment of localized infections caused by M. chelonae or M. abscessus is clarithromycin combined with one of the injectable agents. Amikacin and cefoxitin are effective against $M$. chelonae and $M$. abscessus, whereas ciprofloxacin and doxycycline are not [12]. A minimum of 3 months of antibiotic therapy, or at least 3 to 6 weeks of antibiotic therapy after wound healing has been recommended to prevent recurrence [2]. Although the optimal length of antibiotic therapy has not yet been established, recent work has recommended that antibiotics should be used for 6 to 12 months $[3,13]$. If clinical 
improvement is seen after 2 to 4 weeks of treatment, the route of drug administration can be switched from intravenous to oral. The initial antibiotic regimen can be readjusted when the results of susceptibility testing become available [6].

The species of rapidly growing mycobacteria (RGM) capable of producing disease in humans belong primarily to the $M$. fortuitum group, the M. chelonae/abscessus group, and the M. smegmatis group. Key features for identification of these groups are the presence of typical long-chain fatty acids known as mycolic acids; growth within 7 days of readily visible colonies on primary isolation on multiple types of solid media; arylsulfatase activity within 3 days or 2 weeks; and the absence or delayed appearance of any pigmentation $[1,12]$. RGM are extremely hardy and thrive in even the most hostile environments. Additionally, RGM are resistant to disinfectants and biocides such as organomercurials and chlorine. These hardy RGM species are commonly seen in municipal tap water. Because of their ubiquity, human RGM infections have been reported from most geographic areas in the world, and species of RGM have been recovered from 30 to $78 \%$ of soil samples throughout the United States [12].

Diagnosing RGM infections is difficult. When cultures as well as Gram and AFB staining of specimens are all negative, RGM infection should be considered. NTM cultures and PCRbased assays are essential in making the diagnosis of nontuberculous mycobacterial infection. Combination antibiotic therapy plus drainage of surgical abscesses was found to be effective for our patients. But neither the standard regimen nor the exact dosage of antibiotics has been firmly established. Therefore, the findings of this study may suggest effective treatment options for RGM infections.

\section{REFERENCES}

1. Dailloux M, Laurain C, Weber M, et al. Water and nontuberculous mycobacteria. Water Res 1999;33:2219-28.

2. Muthusami JC, Vyas FL, Mukundan U, et al. Mycobacterium fortuitum: an iatrogenic cause of soft tissue infection in surgery. ANZ J Surg 2004;74:662-6.

3. Jarzembowski JA, Young MB. Nontuberculous mycobacterial infections. Arch Pathol Lab Med 2008;132:1333-41.

4. Sungkanuparph S, Sathapatayavongs B, Pracharktam R. Infections with rapidly growing mycobacteria: report of 20 cases. Int J Infect Dis 2003;7:198-205.

5. Galea LA, Nicklin S. Mycobacterium abscessus infection complicating hand rejuvenation with structural fat grafting. J Plast Reconstr Aesthet Surg 2009;62:e15-6.

6. Murillo J, Torres J, Bofill L, et al. Skin and wound infection by rapidly growing mycobacteria: an unexpected complication of liposuction and liposculpture. The Venezuelan Collaborative Infectious and Tropical Diseases Study Group. Arch Dermatol 2000;136:1347-52.

7. Molecules and Diagnostics Incorporation. REBA Myco-ID product manual. Wonju, KR: Molecules and Diagnostics Incorporation; 2009.

8. Adekambi T, Stein A, Carvajal J, et al. Description of Mycobacterium conceptionense sp. nov., a Mycobacterium fortuitum group organism isolated from a posttraumatic osteitis inflammation. J Clin Microbiol 2006;44:1268-73.

9. Shin S, Kim EC, Yoon JH. Identification of nontuberculous mycobacteria by sequence analysis of the $16 \mathrm{~S}$ ribosomal RNA, the heat-shock protein 65 and the RNA polymerase beta-subunit genes. Korean J Lab Med 2006;26:153-60.

10. Kim BJ, Lee SH, Lyu MA, et al. Identification of mycobacterial species by comparative sequence analysis of the RNA polymerase gene (rpoB). J Clin Microbiol 1999;37:1714-20.

11. Wallace RJ Jr, Brown BA, Silcox VA, et al. Clinical disease, drug susceptibility, and biochemical patterns of the unnamed third biovariant complex of Mycobacterium fortuitum. J Infect Dis 1991;163:598-603.

12. Brown-Elliott BA, Wallace RJJr. Clinical and taxonomic status of pathogenic nonpigmented or late-pigmenting rapidly growing mycobacteria. Clin Microbiol Rev 2002;15:716-46.

13. Kim HR, Kim DW. Soft tissue infection with Mycobacterium abscessus on the chin of a healthy child: a case report. J Korean Soc Plast Reconstr Surg 2010;37:289-92. 